\title{
A construção de si em um grupo de apoio para pessoas com transtornos alimentares
}

\author{
Construction of self in a support group \\ for people with eating disorders
}

\author{
Fabio SCORSOLINI-COMIN \\ Laura Vilela e SOUZA \\ Manoel Antônio dos SANTOS²
}

\begin{abstract}
Resumo
Este estudo teve como objetivo compreender a construção de si mesmo a partir do discurso de pessoas diagnosticadas com anorexia e bulimia, participantes de um grupo de apoio psicológico. Participaram 14 jovens atendidas em um serviço público de saúde de um hospital universitário. A partir do referencial histórico-cultural bakhtiniano, analisaram-se qualitativamente as transcrições audiogravadas de 10 sessões consecutivas do grupo. Constatou-se que os discursos produzidos socialmente sobre os transtornos alimentares são evocados nas falas das participantes e encontram no grupo um espaço para que possam ser contestados, negociados ou aceitos, promovendo a desconstrução de mitos erigidos em torno da enfermidade. A análise empreendida aponta o grupo como uma ferramenta terapêutica significativa para a produção de novos sentidos, não patologizantes com relação aos transtornos alimentares e seus portadores.
\end{abstract}

Unitermos: Anorexia. Bulimia. Dialogismo. Grupos de apoio.

\begin{abstract}
The aim of this study was to understand the discursive constructions of self, made by people diagnosed with anorexia and bulimia, who were participating in a psychological support group. Fourteen young women, who were being attended to in a psychological support group in a public health service at a university hospital, took part in the study. Ten consecutive weekly group sessions were selected and qualitatively analyzed using Bakhtin's historical and cultural approach. Commonly held beliefs about eating disorders were evoked in the participants' words, and were refuted, negotiated, or accepted in the group, furthering the deconstruction of myths about the disorders. The analysis highlights the importance of support groups as a therapeutic tool that enables the production of new, non-pathological approaches to eating disorders and the people diagnosed with them.
\end{abstract}

Uniterms: Anorexia. Bulimia. Dialogism. Support groups.

De acordo com Wolf (1992), a ideologia da beleza é a última das antigas ideologias femininas que ainda tem o poder de exercer controle sobre as mulheres. $\mathrm{O}$ mito da beleza seria materializado não apenas nas dimensões da sexualidade, do trabalho e da religião, mas também do próprio corpo. Segundo a literatura

1 Universidade Federal do Triângulo Mineiro, Instituto de Educação, Letras, Artes, Ciências Humanas e Sociais. Av. Getúlio Guaritá, 159, Abadia, 38025-440, Uberaba, MG, Brasil. Correspondência para/Correspondence to: F. SCORSOLINI-COMIN. E-mail: <scorsolini@psicologia.uftm.edu.br>.

2 Universidade de São Paulo, Faculdade de Filosofia, Ciências e Letras de Ribeirão Preto. Ribeirão Preto, SP, Brasil. 
científica dedicado ao estudo do corpo e da corporeidade (Scorsolini-Comin \& Amorim, 2008), diversos trabalhos apontam a necessidade de romper com as dicotomias existentes no discurso científico (mente-corpo, eu-outro, eu-mundo) e adotar um novo paradigma (Hoogland, 2002; Overton, 1997; Polak, 1997).

Na contemporaneidade, a relação com o próprio corpo é marcada pelo aumento da incidência dos Transtornos Alimentares (TA) na população, entre eles a Anorexia Nervosa (AN) e a Bulimia Nervosa (BN). Esse aumento deve-se, em parte, à ampliação dos estudos dedicados aos mesmos, que vêm possibilitando um maior reconhecimento de sua incidência na população (Dunker \& Philippi, 2003; Sicchieri, Santos, Santos \& Ribeiro, 2007). Esses estudos buscaram delinear a etiologia da AN e BN, procurando identificar fatores de risco para o seu aparecimento (American Psychological Association - APA, 2006). Anorexia e bulimia são consideradas transtornos psiquiátricos e não apenas exagero de valores sociais dominantes, que permeiam ações e adições contemporâneas. São transtornos da conduta alimentar, cuja prevalência tem crescido nas últimas décadas, atingindo principalmente adolescentes e jovens mulheres. Nos últimos anos tem se observado o aumento do número de homens acometidos (Andrade \&Santos, 2009).

Esses quadros psicopatológicos têm sido reconhecidos por sua complexidade, já que mobilizam aspectos emocionais, físicos e sociais da vida do paciente e de seus familiares (Santos, Oliveira, Moscheta, Ribeiro \& Santos, 2004). Atualmente, firmou-se uma convicção de que se tratam de transtornos multifatoriais. A despeito dessa presumida multicausualidade, a pressão sociocultural para ser magro é referida por vários autores como fator de risco para o desenvolvimento da psicopatologia (Giordani, 2006; Polivy \& Herman, 2002). Incluem-se nesse cenário, principalmente, as pressões exercidas pela família, pelos grupos de pares e pela mídia, que podem alimentar a espiral da magreza excessiva.

Para Souza e Santos (2007), a conceituação da AN e BN como psicopatologias reproduz as ideias sociais dominantes encontradas no discurso científico, que são reguladas por intermédio da linguagem. Os discursos vigentes na época contemporânea sobre AN e BN posicionam as pessoas diagnosticadas de maneira particular. À medida que são reproduzidos, eles se legitimam e criam determinadas possibilidades, ao passo que limitam outras, dentro de um contexto cultural específico (Filgueiras et al., 2007; Moreira, Nogueira \& Rocha, 2007; Souza \& Santos, 2009a, 2009b). A fim de contribuir com essas reflexões e ampliar o conhecimento existente, no presente trabalho foi focalizado a construção dos discursos e a produção de sentidos de pacientes integrantes de um grupo de apoio psicológico acerca da construção de si mesmo. Nesse percurso de pesquisa, serão evocados alguns diálogos partilhados no contexto grupal e serão analisados de acordo com o pensamento bakhtiniano. Bakhtin $(1997 ; 1999)$ marcou época como uma das figuras mais importantes do século $X X$, sendo considerado um grande pensador $\mathrm{e}$ teórico da linguagem.

A construção de si mesmo, na abordagem bakhtiniana, pode ser entendida como o processo intermediado pelas noções de dialogismo e polifonia (Bakhtin, 1997; 1999), na medida em que os diferentes discursos, vozes, concepções e práticas são apropriados pelo sujeito em um dado contexto cultural. Nesse movimento de apropriação, o sujeito passa a ser uma co-construção, juntamente com outras alteridades constituintes. Assim, é possível entender o outro de uma maneira original, pois ele é referido não como alguém que está fora de mim, que é estranho a mim, mas como alguém que me constitui, que contribui para o processo de construção de um eu que não me pertence integralmente e que existe a partir do olhar do outro.

Nesse sentido, a concepção dialógica contém a ideia da relatividade da autoria individual e, por conseguinte, o destaque do caráter coletivo e social da produção de discursos. Para Bakhtin (1997), o ser humano deve ser apreendido como um ser que se constitui na e pela interação, ou seja, sempre em meio à complexa e intrincada rede de relações sociais de que participa constantemente. Desse modo, a construção de si mesmo deve ser situada nesse contexto dialógico.

O dialogismo é um conceito que permeia toda a obra de Bakhtin. Tal conceito pode ser definido como o princípio constitutivo da linguagem, o que significa que toda linguagem, em qualquer campo, está impregnada por relações dialógicas. Nessa vertente teórica, o dialogismo seria o confronto das entoações e dos sistemas de valores que possibilitam as mais variadas 
visões de mundo acerca de um tópico específico (Bakhtin, 1997; 1999).

Bakhtin $(1997 ; 1999)$ emprega a palavra polifonia para descrever o fato de que o discurso resulta de uma trama de diferentes "vozes", sem que haja a dominação de uma sobre as outras. Uma das características básicas do dialogismo bakhtiniano é conceber a unidade do mundo como polifônica. Segundo a teoria polifônica de Bakhtin, a palavra é a revelação de um espaço no qual os valores de uma dada sociedade se explicitam e se confrontam. A palavra se transforma e possibilita diferentes significados segundo o contexto em que é enunciada. Na polifonia, a recuperação do coletivo se faz via linguagem, na qual o outro é uma presença constante, já que a linguagem é uma realidade intersubjetiva e essencialmente dialógica. Nessa concepção, o indivíduo é sempre atravessado pela coletividade.

A partir da concepção de polifonia pode-se situar o conceito de construção de si como constituída por um feixe de vozes que se entrelaçam e habitam o si mesmo. Isso marca a diferença entre o pensamento bakhtiniano em relação a outros teóricos da identidade. O que está em jogo, nesse caso, é uma concepção de identidades plurais.

Por essa vertente propor-se ir ao encontro da literatura da área de transtornos da conduta alimentar. Como notaram Andrade e Santos (2009), os estudos publicados raramente dão voz às pessoas que estão no epicentro do sofrimento, como pacientes e seus familiares. Também no plano da assistência, as múltiplas vozes que se interligam, ao constituírem esse campo denso da experiência humana, são simplesmente ignoradas ou restam desacreditadas e frequentemente negligenciadas no contexto das intervenções em saúde.

Pode-se postular, a partir dos estudos que acoIhem os discursos e sentidos produzidos pelas pessoas afetadas, que a exuberância polifônica que configuram os TA evidencia as múltiplas possibilidades de compreensão que decorrem dos modos distintos de dar voz aos falantes. Tal multiplicidade e construção coletiva dos discursos podem ser corporificadas nas falas das pacientes e o grupo de apoio pode ser um espaço privilegiado não apenas para a deflagração dessa multiplicidade, como também para a construção e reconstrução dessas práticas discursivas, a partir da experiência de cada membro integrante. A intervenção em grupo no contexto dos transtornos alimentares tem sido investigada nos últimos anos (Santos, 2006; Souza \& Santos, 2006; 2009 a; 2009 b), destacando-se a importância de valorizar as narrativas das pacientes na compreensão do sofrimento implicado na experiência subjetiva desses quadros. As intervenções psicoterapêuticas ainda são maciçamente calcadas na modalidade individual (Kreling \& Santos, 2005), o que salienta a necessidade de novos estudos que se proponham a investigar as potencialidades terapêuticas dos grupos.

Considerando esses pressupostos, o presente estudo buscou explorar as diferentes versões e descrições de si mesmo presentes em pessoas diagnosticadas com TA, privilegiando-se o grupo de apoio como estratégia de produção de sentidos.

\section{Método}

\section{Participantes}

Participaram do estudo 14 jovens diagnosticadas com TA, com idades entre 19 e 32 anos, sendo nove com diagnóstico de AN e cinco de BN.

O grupo de apoio psicológico acontece como parte do atendimento prestado às pessoas com TA em um serviço público de saúde de um hospital universitário de uma cidade do interior paulista. Trata-se de um serviço especializado pioneiro no tratamento de AN e BN, em funcionamento desde 1982 (Sousa \& Santos, 2009b). 0 grupo é aberto e acontece uma vez por semana. Tem uma hora e 30 minutos de duração e é coordenado por dois psicólogos.

Do ponto de vista de sua composição, o grupo é constituído por pacientes de ambos os sexos, com amplo predomínio do gênero feminino e idade variando entre 16 e 45 anos. No contexto sob investigação, não existem temas pré-agendados, ou seja, os coordenadores oferecem ampla liberdade para os pacientes conversarem sobre assuntos que consideram importantes e que desejem compartilhar com os demais, dentro de uma atmosfera permissiva e acolhedora. São encorajadas as posturas que a literatura tem enfatizado como promotoras de mudanças terapêuticas, tais como a auto-revelação, catarse, experiência emocional corretiva, aprendizagem interpessoal e aprendizado a partir da troca de experiência com os pares (Santos, 2006; Souza \&Santos, 2006; Yalom, 1995). 


\section{Procedimentos}

Adotou-se neste estudo uma abordagem metodológica qualitativa, considerando que a coleta de dados transcorreu em condições naturalísticas, segundo um enfoque descritivo e exploratório de pesquisa. $\mathrm{Na}$ escolha da estratégia metodológica também foi levado em consideração o fato de que a coleta, sistematização e análise dos dados, realizadas de acordo com os princípios que ordenam a abordagem qualitativa, é capaz de subsidiar a compreensão do dialogismo presente no contexto do grupo de apoio. Dentre as diversas estratégias de pesquisa existentes nesse campo, há aquela que dá ênfase à observação sistemática de grupos; nesse tipo de estratégia se operam com registros obtidos de forma manuscrita ou eletrônica.

Nessa vertente, para o presente estudo foram consideradas 10 sessões consecutivas do grupo de apoio psicológico aos pacientes, que foram audiogravadas em fitas K-7 com auxílio de um gravador portátil, colocado no centro do círculo grupal. No início de cada sessão os pesquisadores informavam aos participantes os objetivos da pesquisa e liam o Termo de Consentimento Livre e Esclarecido. Uma vez obtida a anuência e colhidas as assinaturas da totalidade dos participantes, iniciava-se o processo de audiogravação da sessão. Era condição sine qua non para o registro de cada encontro que houvesse concordância unânime dos membros do grupo, caso contrário a reunião prosseguiria sem audiogravação e o material produzido daquele encontro seria descartado da pesquisa.

Os registros audiogravados foram posteriormente transcritos na íntegra e de forma literal, constituindo o corpus de análise da pesquisa. Esse material, constituído pelas transcrições integrais das sessões, foi analisado seguindo o esquema de eixos temáticos (Minayo, 1994), a partir da leitura exaustiva e do destaque das unidades de significado que emergiram dos registros das falas das sessões de grupo. Uma vez obtidos os eixos temáticos, realizou-se a análise com base no referencial bakhtiniano, resgatando em que medida a tessitura desses discursos e saberes em torno da enfermidade e em torno das pessoas portadoras pode ser compreendida como expressões da construção de si mesmo. Essa elaboração tem como interlocutores os participantes do grupo de apoio e as múltiplas vozes sociais que são presentificadas nas falas dessas pessoas, durante o acontecer grupal, de acordo com as noções de dialogismo e polifonia que ancoram nossa compreensão do fenômeno da construção de si mesmo.

Todos os procedimentos éticos preconizados para as pesquisas com seres humanos foram respeitados no percurso de elaboração da pesquisa. O projeto foi aprovado pelo Comitê de Ética em Pesquisa da instituição hospitalar na qual o grupo de apoio acontece (Protocolo n 3542/98). No início de cada sessão os pesquisadores enfatizaram o caráter voluntário da participação e asseguraram a possibilidade de recusa ou de retirada, a qualquer momento, do consentimento formalizado, sem que isso implicasse em prejuízo ao direito a prosseguir em atendimento no serviço e no próprio grupo. Os nomes dos participantes referidos neste estudo são fictícios, de modo a preservar-lhes o direito ao anonimato e à confidencialidade das informações.

\section{Resultados e Discussão}

\section{Construindo o que é ser uma pessoa com anorexia e bulimia}

Nas sessões de grupo o discurso sobre a construção de si mesmo da pessoa com AN e BN vai, gradualmente, se delineando e tomando forma, até se materializar em falas que veiculam intenso sofrimento emocional. As participantes se descrevem como pessoas com um modo de ser e estar no mundo absolutamente único, dissonante das demais pessoas com as quais convivem, incluindo os familiares. Posicionam-se, assim, como um grupo de pessoas com concepções bem particularizadas que, ao compartilharem seus problemas, dividem também características identitárias semelhantes:

Com certeza. Eu acho que ninguém melhor pra compreender o que é essa doença, o que você sente, o que você passa, do que a pessoa que tem a mesma coisa. Não é qualquer pessoa que te escuta e que te entende. Nãoéqualquerpessoaquevaiteescutar evaifalar: "eu sei o que vocêestá passando", porque as pessoas te olhame falam assim: "ai, isso aíésó vocêter força devontade, isso aí é só se controlar, isso você consegue, você consegue". Mas não éassim (Catarina). 
As pessoas aí fora geralmente não entendem, não têm noção do que é.... A pessoa tem uma noção de fora, do lado de fora do problema. Então não é a mesma coisa (Olívia).

O grupo funciona como um espaço no qual as vozes em torno do sofrimento subjetivo são compartilhadas, ou seja, as participantes evocam discursos que as identificam e as particularizam, trazendo fortemente a noção de que só podem ser compreendidas por quem atravessa uma experiência semelhante:

Mesmo porque, se você nunca passou por essa fase [começo do tratamento], ninguém entende. A gente entende. Uma entende a outra (Bethânia).

Eu acho que muita coisa lá fora ajudou, a minha família ajudou, sabe? O trabalho, o namorado... Eu acho que tudo isso conta, mas acho que o fato de eu querer vir [ao grupo], pela força de vontade de levantar mais cedo na terça-feira [dia da grupoterapia], não marcar compromissos pra esse dia, tirar esse dia só pra vir aquie tudo, eu acho que tudo isso.... O fato da gente estar aqui não é simplesmente estar aqui. Cê deixou um monte de coisa pralá, deixou... cê decidiu vir. Eu acho que tudo isso é um desafio. Só pelo fato de cêtervencido todos esses desafios, cêjá tá melhorando (Rúbia).

A construção de uma identidade anoréxica ou bulímica parece nascer do olhar de estranhamento das pessoas "lá de fora", que não possuem a mesma visão de mundo peculiar a essas pacientes e que, por viverem essa condição de exterioridade em relação ao seu modo de olhar a vida, não conseguem entender como alguém pode deixar de comer ou, então, vomitar o que come. Como destacado por Giordani (2006), a imagem corporal imersa em um contexto existencial é a revelação de uma identidade, de um sujeito que se constitui na história de suas relações concretas, não apenas uma imagem midiática transitória. Esse sentimento de habitar um mundo à parte, que corporifica a sua identidade pessoal, éveiculado pelas participantes, como é possível apreender nas seguintes falas:

Então éum mundo sónosso, totalmente escondido, pai emãenão sabe. Quando descobrem, pareceque a gente levou uma facada pelas costas e eles acabam não entendendo o que a gente sente. Pra eles édifícil, mas pra gente.... eles têm que ver que pra gente também é difícil comer, se alimentar. A gentevê a comida não com tanto prazer igual eles veem. Hoje eu já vejo a comida com prazer, eu como.... Não, eu tenho dificuldade ainda de comerarrozefeijão (Bethânia).
Eles não veem que eu tô doente, e falam que eu tô com uma doença invisível, e ficam tirando sarro da minha casa. [enraivecida]. Tem que ver pra crer, e dá vontade de quebrar um braço, dá vontade de quebrar uma perna pra saber que eu tô doente. Emostrar [com um tom de vozáspero]. Porquequando eles me vêem inteirinha, eles me criticam e tiram sarro da minha cara. Efalam pra eu ir trabalhar mesmo, pra deixar de ser preguiçosa. Enão veem que eu não dou conta... (Brigite).

A experiência de sentirem-se diferentes parece ser confirmada por meio do olhar de seus familiares e pessoas da comunidade com quem convive cotidianamente. Se por um lado esse sentir-se diferente leva à convicção de que se é uma pessoa única e incomparável, funcionando como suporte identitário, por outro lado promove um penoso sentimento de exclusão e desamparo, uma vez que se sentem deslocadas em um mundo que não oferece um lugar seguro para acolhê-las:É, a minha mãeera assim. Édifícil viverno mesmo teto que uma pessoa que não entende a gente.... Mas assim, realmente... aí é muito difícil quando a pessoa não acredita (Olívia).

Aproxima-se com outras pessoas que trilham o percurso do tratamento intensifica a vivência de identificação entre as participantes do grupo. A partir da interanimação dialógica é possível perceber a construção de um discurso próprio de quem vivencia experiências com conteúdos similares. A coesão grupal é favorecida na medida em que as participantes compartilham a percepção de que os outros (quem "está de fora") nomeiam suas manifestações de "doença", caso se situem no plano do discurso biomédico, ou de "preguiça" - estratagema supostamente utilizado para tirar vantagem da situação e "não trabalhar", caso permaneçam nos limites do discurso moralizador.

Situam-se, assim, em meio ao cruzamento de sentidos socialmente construídos para os TA: entre "doença" e "preguiça". Há necessidade de delinear e reforçar as fronteiras desse mundo próprio, que de certo modo coincide com os limites da identidade que está sendo construída, sendo que apenas quem vivencia ou vivenciou a anorexia e a bulimia tem a chave que dá acesso a esse mundo particular e pode compreender a singularidade de suas experiências. A rejeição sentida por parte das pessoas que não entendem o seu modo de ser fomenta a necessidade de se reconhecerem como 
iguais no grupo, renunciando parcialmente ao isolamento social marcante em que vivem.

A tomada de consciência de que outras pessoas talvez possuam as características comportamentais, problemas ou conflitos similares, relaciona-se a um fator terapêutico grupal descrito na literatura como universalidade (Block, Reibstein, Crouch, Holroyd \& Themen, 1979; Yalom, 1995). Esse fator seria responsável pelo rompimento do isolamento vivido pelo paciente, que muitas vezes se sente desmoralizado e fragilizado, abrindo a possibilidade de intercâmbio social franco e honesto. A sensação provocada por perceber outras pessoas em estado de sofrimento semelhante é a de alívio, que promove melhora da auto-estima e redução do estigma social.

Nesse sentido, o grupo oferece um espaço no qual as pessoas diagnosticadas com TA podem atualizar suas experiências de vida. Podem ser ouvidas e, em certas circunstâncias, sentirem-se verdadeiramente compreendidas. Essa compreensão se alicerça no acolhimento dos pares e na identificação com seu sofrimento, favorecendo a proximidade com o que é percebido como semelhante no diálogo com o outro.

Tal compreensão, que só pode ser operada pelo outro - um outro que passou ou que ainda passa pela mesma experiência de sofrimento - se instaura no espaço do grupo, uma vez que é nesse contexto microssocial que as participantes identificam um âmbito protegido em que as diferentes experiências podem ser narradas. Essas narrativas evocam o conceito de polifonia de Bakhtin (1999), na medida em que corporificam as múltiplas vozes que vão ser responsáveis por construir uma noção do que é atravessar a experiência de viver com uma grave perturbação do comportamento alimentar. Nesse diálogo tecido por várias vozes, as participantes se remetem também às vozes de outras pessoas, dos seus conhecidos, familiares, vizinhos e amigos, e que lançam sua compreensão sobre o que é estar do "lado de dentro" desse universo particularizado. Essas vozes revelam o modo como os outros as veem, sendo que a marca que as distingue dos demais é justamente aquilo que é depreciado e estigmatizado como "doença" ou "preguiça", que ganha legitimação seja no discurso do senso comum, seja no discurso biomédico. Nota-se, assim, que o "outro" é comumente definido por sua condição de exterioridade em relação ao universo 472 próprio do transtorno.
O outro comparece, invariavelmente, nos discursos produzidos como uma instância incriminadora e desqualificante, aos olhos de quem as participantes aparecem como pessoas excêntricas, teimosas, intransigentes, impertinentes, rebeldes, dissimuladas, pusilânimes e destituídas de energia, de força de vontade, conforme explicitado nos seguintes recortes:

Porque você sente [quando as pessoas falam assim]: Isso aí é só mudar, isso aí é uma loucura, você não tem força de vontade, vocênão se esforça, você é teimosa, já ouvi muitas vezes. Você é muito teimosa! Se você quisesse, vocêsaía disso, é só vocêcomer... vocêpensa...étão fácil! Vocêcoloca uma mesa de comida farta, aívocêvai conseguir comer queéuma gracinha. Enãoébem por aí. "Era muito mais prático você comer, você se alimentar, do que ficar nessa tortura toda (Olívia).

Eu percebi que antes de eu ter aquilo no nariz [sonda nasográstica para passagem da alimentação], na minha casa eu era a "fingida", e depois que eu fiz a gastrostomia [abertura feita por uma sonda posicionada diretamente na parede do estômago para passagem de uma dieta especial], a minha família soube tratar mais como doença. Eles estão com mais cuidado. Eu penso assim, que precisou acontecer esse desgaste comigo praeles perceberem queeu tô com essa doença (Dália).

O meu paijá quebrou uma costela minha, me batendo, porque eu não queria comer. ... meu pai chegou e falou: Cê vai comer. Eu não vou comer, eu não tô com fome, passei o dia fora. Elefalou: 'Miriam, vaicomer, que cênão comeu nada hoje.' Eu fiquei revoltada, porque eu falei assim, pensei assim: Como que eles falam que eu não cominada hoje, se eu passei o dia fora, se eu tenho medo de mim? Ele tá me acusando de uma coisa que ele não sabe seéverdade. Eeu tinha comido. Eu tinha passado o dia na academia, desde as seis da manhã, mas eu comi dois lanches naturais. Então eu falei assim: Não, eu não vou comer. Não tô com fome. Aío meu paifalou: 'Não, cê vai comer, senão eu vou enfiar a comida pela sua boca.' Eufalei assim... levanteiefaleiassim: Vou comer... (Miriam).

Deste outro, percebido como hostil, invasivo e perigoso, é preciso defender-se tenazmente, resistir às suas investidas, erigindo uma barreira fortificada. Essa muralha rígida vai ser reforçada mediante o recrudescimento dos sintomas, que mantêm a paciente afastada tanto da comida como do outro intrusivo. Assim, é possível dizer que o modo como o outro é engendrado 
no discurso revela uma montagem que não permite senão a formação de uma identidade reativa, como proteção à intromissão violenta que desestabiliza a construção de si.

Ouvidas em seu conjunto, amalgamadas no movimento de entrelaçamento e sentidos proporcionado pelo grupo, as falas das pacientes acabam por construir uma determinada concepção de identidade, tecendo uma noção de pertencimento a um grupo específico, que somente elas conheceriam em sua essência e no interior do qual podem construir formas alternativas de ser relacionarem. Essa tarefa, se bem conduzida, pode permitir-Ihes recuperar a capacidade perdida de poder transitar entre os "mundos": o mundo da enfermidade e outros mundos possíveis, a serem construídos.

\section{Os discursos dos outros: a contundência do olhar que vem de fora}

Como destaca Bakhtin (1997; 1999), o olhar que lançamos a nós mesmos não é neutro, mas constituído pelo olhar do outro, que está fora de nós. As múltiplas vozes que são evocadas nas falas das pacientes refletem o modo como a cultura e a sociedade as vêem, mas também como elas próprias passam a se ver através do olhar do outro. Esses olhares são construídos socialmente e se expressam de modo muito claro quando as participantes do grupo narram a forma como são vistas pelas outras pessoas.

Esses discursos, decodificados pelo princípio dialógico, não são de autoria exclusiva de uma dada pessoa ou de determinada instituição. Tais discursos são produzidos dentro dos limites dos repertórios interpretativos oferecidos por uma dada sociedade, com determinados valores hegemônicos estabelecidos, posturas sancionadas e preconceitos arraigados. Nas falas seguintes destacamos alguns discursos sociais difundidos maciçamente pelo senso comum sobre a AN e BN, que são reproduzidos no grupo pelas participantes. Nessa reprodução, esses discursos dominantes podem ser legitimados e ratificados como vozes definidoras de sua identidade, mas também podem ser desconstruídos e retificados, dependendo do modo como são acolhidos e significados pelos demais:
Eo meu pai também era assim, ele não aceitava que eu era doente, ... dizia que eu só comia porcariada, e comida eu não comia, e pro meu pai, eu ter engordado, então, eu não tava doente. Quando eu comecei a ir na nutricionista, que eu... não sei... eu vique eu tava comendo errado, eque eu tava engordando muito, ele já falou que tava com frescura, que eu não tava doente. Ele não aceitava, eeu ia na psiquiatra, e ele não aceitava, ele me cobrava que eu comesse (Frida).

As pessoas falam: cê tá ficando louca?.... Cênão precisa disso, cê tá bonita (Miriam).

Porque o que me deixa mais assim, magoada, é, por exemplo, meu irmão. Eu tenho ele mais como um filho, e agora inverteu as coisas, né? Porque agora é ele que quer dar lição de moral pro meu lado, né: Chega desse trelelê, vamos lá almoçar, pega o prato, vamos comer, e que não sei o quê... (Olívia).

Essas falas mostram como a pessoa com AN é, geralmente, vista pela sociedade. Sobre ela recaem estigmas e preconceitos, que as colocam em uma posição de portadora de uma estranheza que se expressa em atitudes bizarras frente às necessidades corporais (Fraga \& Santos, 2005). Esse fenômeno, de certo modo, as mitificam como seres extemporâneos, quase incorpóreos e desencarnados, que "escolhem", de modo consciente, transitar à margem da vida. Como explicitado em suas falas, elas são identificadas como pessoas "magras,",loucas", "teimosas", "difíceis," "volúveis" e "caprichosas". Esses rótulos as categorizam como pessoas rígidas e obstinadas na sua visão distorcida da vida, na tenacidade de levar adiante suas crenças e convicções consideradas delirantes.

Os profissionais de saúde muitas vezes reproduzem esses estereótipos do senso comum e passam a reconhecê-las como pessoas tenazes, mas, contraditoriamente, seres frágeis e destituídos de força de vontade para mudar, pois não se esforçam minimamente para modificar sua perspectiva de vida. Essa imagem é corroborada pela influência da mídia e pela forte veiculação dos TA como matéria de interesse em diversos veículos informativos contemporâneos. A imagem do que é "ter" um desses transtornos não é constituída apenas a partir da auto-imagem das pacientes, mas forjada e alimentada pelos discursos produzidos pelos diversos "outros" sociais. Essa construção não se dá de modo linear, como nos aponta Bakhtin (1999), mas opera a partir de inúmeras tensões, no interior de um jogo 
ininterrupto de negociações de saberes, posições e práticas que dão conformidade ao que, socialmente, é reconhecido como TA na era contemporânea.

\section{O medo do outro}

Nos discursos que as participantes constroem acerca da AN e da BN encontra-se claramente delineado o medo de se ver de forma especular no outro, de se identificar em demasia com o interlocutor e, assim, perder os contornos da própria identidade. Quando narram a respeito da obesidade - que é identificada como ameaça permanente que apavora a todas - as pacientes mostram uma rejeição pelo que seria uma projeção futura de um possível devir. Na fala de uma das participantes do grupo:

Entãoédifícil, as pessoas não entendem, ficam, encaram, olham.... Evocêaindafica na sala deespera compacientes de diferentes tipos, como paciente que vaipara a cirurgia de redução de estômago, e você tá ali vendo bastante obeso na sua frente. Eu tô morrendo de medo daquilo lá... de você virar um daquele tamanho. Eu sei que ele também tem uma doença, como a gente tem, que ele tem as dificuldades como as nossas, nós somos assim tidos como diferentes, porque sem querer ou não, por onde vocêpassa o pessoal te encara pelo corredor (Olívia).

Nessa fala é possível notar, ainda, que há uma identificação com o desviante, no sentido de compreender como essas pessoas "diferentes" ("anoréxicas", "bulímicas", "obesas") são reconhecidas socialmente: nós somos assim, tidas como diferentes. O discurso de Olívia, apesar de rejeitar o que, aparentemente, afigura-se como o seu "oposto", mostra-se ambivalente, na medida em que, ao um só tempo, rejeita e incorpora o sofrimento do outro ao seu, identificando-se com ele nesse aspecto. Assim, pode-se pensar de que modo ocorre a construção, em nível social, da imagem que se projeta acerca da pessoa diagnosticada com TA. Como esses discursos são conjugados, dialogados, encarnados e corporificados pelas pacientes? No episódio aqui descrito pela paciente, cujo peso nunca excedeu os 33 quilos em 15 anos de tratamento ininterrupto, ela narra o medo de chegar a uma condição de obesidade mórbida semeIhante à situação vivenciada pelas pessoas super-obesas, que estão em busca da gastroplastia, popularmente conhecida como cirurgia de "redução de estômago". Nesse contexto, essa intervenção cirúrgica é percebida como o "fim da linha" da pessoa obesa e representa o temor que as pacientes com AN e BN apresentam de perderem o controle sobre sua voracidade e atingirem esse estágio extremado de excesso de peso. O que se observa, na prática, é que elas, em sua maioria, não apresentam quadro de sobrepeso e sim de subpeso, o que não justificaria, em termos racionais, essa preocupação. Esse medo mórbido de engordar traduza própria configuração do pensamento distorcido que caracteriza a percepção da imagem corporal da pessoa acometida porTA.

O modo de encarar o descontrole do comportamento alimentar, no excerto apresentado, é revelado a partir do olhar, que embute o julgamento das outras pessoas. Essas pessoas representam os diversos discursos criados e, continuamente, desconstruídos e recriados, acerca dos indivíduos que desenvolvem essa problemática. As pacientes, no espaço grupal, revelam o modo como o olhar externo, sentido como devastador, regula as suas próprias atividades, julgamentos, percepções e sentimentos. É um olhar intrusivo e penetrante, que as devassa de modo insistente, deixando-as temerosas, vigilantes e, permanentemente, na berlinda, em uma posição defensiva. Por outro lado, esses saberes construídos e reiteradamente reconstruídos no espaço discursivo não pertencem a uma ou outra pessoa, pois são patrimônio comum a uma coletividade que transforma tais discursos e os incorpora em suas práticas sociais e em suas visões de mundo. Visões acerca do que é ser "gordo", do que é ser "magro", do que é ter a vida estagnada por um TA, entre outras possibilidades.

\section{Convivendo com o outro: rompendo o casulo}

Os discursos produzidos socialmente se mostram, entre outros marcos, no diálogo e nas interações estabelecidas com os diversos outros sociais. Como salientado pelas participantes do grupo, esse convívio nem sempre é harmônico ou isento de tensões e conflitos, uma vez que as pessoas que não apresentam exatamente o seu modo de viver seriam incapazes de compreender de que modo se dá o sofrimento daquelas que têm TA. Retomando a discussão acerca da construção da identidade de pacientes com AN e BN, é possível ponderar, a partir dos discursos que elas tecem no enquadre grupal, que apenas quem passou ou quem 
ainda passa pelas agruras do problema têm a real dimensão da experiência - e, portanto, legitimidade para aquilatarem as repercussões, dificuldades e nuanças de ser anoréxica ou bulímica.

Ao mesmo tempo em que esse movimento marca a ideia da universalidade presente como um cimento da coexistência em grupo (Yalom, 1995), destaca a situação de exclusão social sentida por essas pacientes, uma vez que elas acreditam que só podem ser compreendidas por si mesmas, ou seja, pelas pessoas que experienciam a enfermidade, o que exclui de seu espaço de sociabilidade aqueles que portam outras visões, experiências e valores. Isso marca um lugar social específico no qual essas pacientes escolhem viver, um lugar que não pode ser ocupado por pessoas diferentes - que são aquelas pessoas socialmente reconhecidas como "normais". Desse modo, elas creem habitar um universo singular e hermeticamente fechado, o que ajuda a compreender o estado de ensimesmamento, que se traduz em intenso retraimento social e empobrecimento da vida relacional. Nesse processo de autoencapsulamento, não resta espaço para a alteridade ser reconhecida como tal e, assim, não é possível romper o casulo fortificado que tem no corpo seu último bastião.

Então quando eu criei... eu queria o mundo das anoréticas, que só tinha importância o meu mundo, nada do que tava ao redor de mim tinha importância. Então eu fui vendo que eu estava, assim, desfalecendo, desmaiando demais. Então eu não queria morrer, porque eu tinha medo de morrer, só que eu também não queria comer (Bethânia).

Este excerto mostra com clareza o entrincheiramento da paciente no que ela própria designa como "mundo das anoréticas". O discurso intolerante em relação ao diferente é algo que emana não apenas das pessoas ditas normais em relação às anoréxicas, mas também no sentido inverso: anoréxicas e bulímicas, muitas vezes, não suportam o contato com as pessoas supostamente normais porque se sentem alvos de discriminação por parte de um olhar inquiridor e discriminador, como se pode apreender no segmento discursivo a seguir.

Festa... você se sente diferente. Quando tem festa no trabalho pra mim é uma tortura, tudo gira em torno de comida, eu ficolásem comereo pessoal: cênãovaicomer nada? Eles falam assim: come, e não seio quê. A hora que cê cisma que vai experimentar alguma coisa pra satisfazer alguém: 'ai, vou tirar uma foto de você comendo, nunca te vi comendo, eu preciso fotografar esse momento' (Olívia).

\section{Considerações Finais}

Nas dobras dos processos interacionais que se estabelecem, o grupo de apoio tem se mostrando um espaço privilegiado para que se possa apreender o princípio dialógico. Aqui cabe a ressalva de que o dialogismo, enquanto um princípio de linguagem, subjaz a todas as produções de um falante, ou seja, já está presente em todo contato humano, como algo constitutivo da condição humana (Bakhtin, 1999). Como seres de diálogo, seres de linguagem, somos inapelavelmente engendrados nas malhas discursivas produzidas nos encontros dos quais participamos e nos relacionamentos nos quais nos engajamos.

A utilização do referencial teórico bakhtiniano para a compreensão dos diálogos que emergem no grupo de pacientes mostrou ser um recurso apropriado para o entendimento dos resultados e suas implicações. A concepção dialógica, que preconiza a relatividade da autoria individual e, portanto, dá destaque ao caráter coletivo e social da produção discursiva, oferece uma contribuição original para o campo investigado.

O destaque posto no caráter dialógico das falas das participantes de um grupo que acontece no contexto da assistência em saúde se justifica porque poucos tratamentos abarcam essa noção, tentando compreender a multiplicidade dos contatos estabelecidos entre as pessoas, com suas nuanças e necessidades próprias. É imperativo que reflitamos, como profissionais de saúde, em que medida poderemos oferecer novas propostas de tratamento mais humanizado e sintonizado com as demandas subjetivas das pessoas.

Nosso ponto de vista é que os tratamentos deveriam privilegiar os espaços grupais, onde os pacientes pudessem, por meio da valorização da palavra e do contato interpessoal, narrar suas vivências e tirar proveito da riqueza das interações estabelecidas. Nesse contexto, é preciso ter em vista o caráter coletivo, polissêmico e polifônico da produção das ideias, discursos e sentidos que situam as pessoas em um determinado contexto discursivo. A consideração prática desse princípio deveria ser um dos eixos norteadores dos 
tratamentos, reduzindo a excessiva ênfase que é dada ao modelo biomédico, que direciona nosso olhar para os sinais e sintomas da doença. A prática clínica pode se beneficiar quando transferimos essa visão para um olhar integral à pessoa doente, em sua mútua constituição pelo outro e pelo ambiente.

Os discursos atuais sobre AN e BN são limitadores, no sentido de que veem os pacientes como pessoas doentes, que apenas recebem passivamente - ou rejeitam radicalmente - os discursos elaborados por outrem, sem uma elaboração pessoal. Prevalece ainda uma visão patologizante, que favorece uma compreensão linear e unívoca desses quadros. No presente estudo pontuamos que a multiplicidade de discursos é produzida socialmente e não se situa em um ou outro falante. Deve-se compreender que, do mesmo modo com que as pessoas, no espaço social das interações cotidianas, constroem determinados discursos sobre a AN e a BN que terminam por aprisioná-las, ao fixarem modos de perceber e decodificar suas múltiplas expressões, esses discursos também podem ser transformados, abarcando outras possibilidades e visões alternativas acerca do problema. Apostar na potencialidade das construções interpretativas alternativas é um auxílio valioso para romper dicotomias cristalizadas tanto no discurso científico como do senso comum. Nesse sentido, o presente estudo defende uma compreensão alternativa ao tradicional conhecimento biomédico. É uma aposta pela via do discurso e da linguagem, porém, sem desconsiderar a etiologia multidimensional do problema. Como foi destacado na introdução, há uma multifato-rialidade que envolve a produção social dos sintomas de AN e $\mathrm{BN}$, o que desautoriza qualquer pretensão de engendrar um conhecido absoluto, que nos induza a acreditar que a construção de sentido, única e exclusivamente, pode dar conta de sustentar os sintomas.

Considerando esses limites, perceber no grupo um contexto facilitador da produção de novos sentidos pode contribuir para ampliar os repertórios interpretativos dos seus participantes. O que pode repercutir em práticas mais saudáveis e visões menos estigmatizantes, não patologizantes, mais inclusivas e promotoras de desenvolvimento psicológico. Pessoas com AN e BN podem e devem ser vistas e concebidas a partir dessa ótica humanizadora. Porém, a perspectiva dialógica aqui apresentada não pode se sobrepor ou obscu- recer outros enfoques, incluindo as mais patologizantes. Como visões de mundo, as diferentes abordagens devem ser compreendidas como leituras possíveis e não necessariamente excludentes. Não podemos recair no maniqueísmo de desqualificar as outras vertentes compreensivas, mas sim possibilitar que as diferentes visões convivam, se complementem e revelem sentidos até então insuspeitados, que encorajem práticas e reflexões inovadoras.

Assim, priorizando o caminho aqui delineado, destacamos que devemos contextualizar a produção dos discursos, situando a fala das pessoas com AN e BN dentro do âmbito específico em que ela se enuncia. Uma visão descontextualizada é intrinsecamente essencialista, pois tenta naturalizar as causas do sofrimento esculpido nos corpos e mentes das pacientes, podendo contribuir para que se perpetue a visão preconceituosa e estigmatizante que, habitualmente, é endereçada às pessoas com diagnóstico de TA. O cuidado deve abarcar, de modo coerente e completo, a pessoa em sua multiplicidade, em seu caráter dialógico, que emerge na sua relação com o outro e com o mundo. Compreendendo o caráter coletivo das produções das ideias e dos discursos, que situam as pessoas em um determinado contexto discursivo (Spink \& Medrado, 2000), pode-se nortear os tratamentos existentes na atualidade, diminuindo o excessivo valor que se dá ao déficit eà doença, transferindo a ênfase à pessoa em seu processo de significar seu sofrimento, em sua constituição com e pelo outro, nos marcos de seu ambiente, de sua história e circunstâncias de vida.

Como produto social, nossa fala está impregnada das palavras dos outros, o que nos coloca como ativos produtores da discursividade. Assim, as ideias hegemônicas que circulam nos espaços sociais sobre os TA podem ser rebatidas pelo mesmo princípio dialógico, o que permite potencializar o valor transformador da experiência de intercâmbio grupal. Considerando a produção histórica dos discursos, o fato de o grupo servir de veículo para que novos saberes sobre a AN e BN possam circular - concepções sobre o transtorno, dimensões do tratamento, modos de enfrentamento, recursos de superação - sem dúvida pode contribuir para desmistificar muitas crenças relacionadas ao problema e às pessoas diagnosticadas com tais transtornos. Nessa vertente, uma das crenças mais cristalizadas e 
que precisa ser desconstruída junto aos familiares é a de que oTA é decorrência de capricho pueril ou simples modismo de adolescentes imaturas, que têm ou um dia tiveram um sonho frustrado de se tornarem modelos.

A julgar pelo que pôde ser captado e analisado nos grupos de apoio, pode-se afirmar que muitos dos mitos tecidos em torno dos TA podem ser gradualmente desconstruídos e reelaborados. O que destacamos aqui é que o conhecimento em torno do princípio dialógico e polifônico da linguagem pode contribuir para que tais ideias sejam não apenas veiculadas, mas ativamente exploradas para atuarem como promotoras de mudanças. O norteador ético do tratamento deve ser a busca de transformações psíquicas que propiciem uma maior qualidade de vida às pacientes, melhores condições de adesão ao tratamento e possibilidades reais de inclusão social. Contextualizar a produção dos discursos, situando as falas das pessoas com AN e BN dentro do meio específico em que são enunciadas, pode contribuir para que não se perpetue a visão desqualificadora e desumanizante que se lança a essas pacientes, quando elas não são consideradas em sua integralidade e dignidade pessoal.

Desse modo, no horizonte dos TA, é preciso que repensemos o conceito de "doença" veiculado na pós-modernidade, tendo em vista a dupla via em que se dá a constituição do ser humano. Considerando o princípio dialógico, é necessário olhar "de dentro para fora", o que só é possível a partir da valorização do discurso dos pacientes, em seu caráter dialógico e multifacetado, que emerge na relação com o outro e com o mundo. Sem essa consideração, qualquer visão acerca dos graves problemas que comprometem o comportamento alimentar será, inevitavelmente, unívoca e empobrecedora, o que nos colocaria, novamente, diante de uma concepção unilateral do ser humano.

\section{Referências}

Andrade, T. F., \& Santos, M. A. (2009). A experiência corporal de um adolescente com transtorno alimentar. Revista Latino-Americana de Psicopatologia Fundamental, 12 (3), 454-468.

American Psychiatric Association. (2006). Practice guideline for the treatment of patients with eating disorders ( $3^{\text {th }} \mathrm{ed}$.). Washington, DC: Author.
Bakhtin, M. (1997). Estética da criação verbal (2a ed). São Paulo: Martins Fontes.

Bakhtin, M. (1999). Marxismo e filosofia da linguagem (9a ed). São Paulo: Hucitec.

Block, S., Reibstein, J., Crouch, E., Holroyd, P., \& Themen, J. (1979). A method for the study of therapeutic factors in group psychotherapy. British Journal of Psychiatry, 134, 257-263.

Dunker, K. L. L., \& Philippi, S. T. (2003). Hábitos e comportamentos alimentares de adolescentes com sintomas de anorexia nervosa. Revista de Nutrição, 16 (1), 51-60.

Filgueiras, M. S. T., Lisboa, A. V., Macedo, R. M., Paiva, F. G., Benfica, T. M. S., Vasques, V. A. (2007). Avaliação psicossomática no câncer de mama: proposta de articulação entre os níveis individual e familiar. Estudos de Psicologia (Campinas), 24 (4), 551-560. doi: 10.1590/S0103-166X2 007000400014.

Fraga, L. B., \& Santos, M. A. (2005). A mortificação do corpo na anorexia nervosa: considerações sobre a função de holding na psicoterapia. In M. A. Santos, C. P. Simon \& L. L. Melo-Silva (Eds.), Formação em psicologia: processos clínicos (pp.163-184). São Paulo: Vetor.

Giordani, R. C. F. (2006). A autoimagem corporal na anorexia nervosa: uma abordagem sociológica. Psicologia \& Sociedade, 18 (2), 81-88.

Hoogland, R. (2002). Fact and fantasy: the body of desire in the age of posthumanism. Journal of Gender Studies, 11 (3), 213-231.

Kreling, D. B., \& Santos, M. A. (2005). Anorexia nervosa: Um relato de atendimento clínico realizado em contexto multidisciplinar. In M. A. Santos, C. P. Simon \& L. L. MeloSilva (Eds.), Formação em psicologia: processos clínicos (pp.143-161). São Paulo: Vetor.

Minayo, M. C. S. (1994). O desafio do conhecimento: pesquisa qualitativa em saúde. São Paulo: Hucitec.

Moreira, V., Nogueira, F. N. N., \& Rocha, M. A. S. (2007). Leitura fenomenológica mundana do adoecer em pacientes do serviço de fisioterapia do núcleo de atenção médica integrada, Universidade de Fortaleza. Estudos de Psicologia (Campinas), 24 (2), 191-203. doi: 10.1590/S0 103-16672007000200006.

Overton, W. (1997). Beyond dichotomy: an embodied active agent for cultural psychology. Culture and Psychology, 3 (3), 315-334.

Polak, Y. N. S. (1997). O corpo como mediador da relação homem/mundo. Texto \& Contexto Enfermagem, 6 (3), 29-43.

Polivy, J., \& Herman, C. P. (2002). Causes of eating disorders. Annual Review of Psychology, 53 (1), 187-213.

Santos, M. A. (2006). Sofrimento e esperança: grupo de pacientes com anorexia e bulimia nervosas. Medicina (Ribeirão Preto), 39 (3), 386-402.

Santos, M. A., Oliveira, E. A., Moscheta, M. S., Ribeiro, R. P. P. \& Santos, J. E. (2004). Mulheres plenas de vazio: os aspectos familiares da anorexia nervosa. Vínculo, 1 (1), 46-51. 
Sicchieri, J. M. F., Santos, M. A., Santos, J. E., \& Ribeiro, R. P. P. (2007). Avaliação nutricional de portadores de transtornos alimentares: resultados após a alta hospitalar. Ciência, Cuidado e Saúde, 6 (1), 68-75.

Scorsolini-Comin, F., \& Amorim, K. S. (2008). Corporeidade: uma revisão crítica na literatura científica. Psicologia em Revista, 14 (1), 189-214.

Souza, L. V., \& Santos, M. A. (2006). A família e os transtornos alimentares. Medicina (Ribeirão Preto), 39 (3), 403-409.

Souza, L. V., \& Santos, M. A. (2007). Anorexia e bulimia: conversando com as famílias. São Paulo: Vetor.

Souza, L. V., \& Santos, M. A. (2009a). A construção social de um grupo multifamiliar no tratamento dos transtornos alimentares. Psicologia: Reflexão e Crítica, 22 (3), 317-326.

Souza, L. V.; \& Santos, M. A. (2009b). A construção de sentidos em um grupo de apoio aos familiares de pessoas com transtornos alimentares. In S. R. Pasian, G. Romanelli \& M.
V. Cunha (Orgs.), Investigação científica em Psicologia: aplicações atuais em saúde (pp.69-84). São Paulo: Vetor.

Spink, M. J. P., \& Medrado, B. (2000). Produção de sentidos no cotidiano: uma abordagem teórico-metodológica para análise das práticas discursivas. In M. J. Spink (Org.), Práticas discursivas e produção de sentidos no cotidiano: aproximações teóricas e metodológicas (pp.41-61). São Paulo: Cortez.

Wolf, N. (1992). O mito da beleza: como as imagens de beleza são usadas contra as mulheres. Rio de Janeiro: Rocco.

Yalom, I. D. (1995). The theory and practice of group psychotherapy. New York: Basic Books.

Recebido em: 14/8/2008

Versão final reapresentada em: 12/2/2010

Aprovado em: 27/8/2010 